\title{
Percutaneous needle biopsy of the lung
}

\author{
D J ALLISON, ANNE P HEMINGWAY
}

\begin{abstract}
A total of 160 percutaneous needle biopsies of pulmonary lesions were performed in 149 patients. Cytological and bacteriological examination of the biopsy material yielded clinically useful information in $87 \%$ of these patients. False-negative diagnoses were made in $6 \%$, but there were no false-positive diagnoses. In most patients the biopsy obviated the need for a diagnostic thoracotomy. The principal complication of the procedure was pneumothorax, which occurred in $24 \%$ of patients; the pneumothorax, however, was usually very small and only two of these patients required treatment with a pleural drain. There were no deaths in the series.

It is concluded that percutaneous needle biopsy is an effective and relatively safe method of obtaining diagnostic material from a pulmonary lesion.
\end{abstract}

\section{Introduction}

The demonstration of a mass. lesion in a chest radiograph presents a diagnostic problem that requires an early solution. If the lesion is malignant information about the cell type is essential for the correct choice of treatment, while the positive diagnosis of a benign condition provides reassurance for patient and doctor, may obviate the need for a thoracotomy, and, in the case of infection, allows identification of the causative organism. Several methods are available for obtaining cellular material from a pulmonary lesion: these include sputum culture and

\footnotetext{
Department of Diagnostic Radiology, Hammersmith Hospital, London W12 0HS

D J ALLISON, MD, FRCR, consultant and honorary senior lecturer, Royal Postgraduate Medical School ANNE P HEMINGWAY, BSC, MRCP, registrar
}

cytology, fibreoptic bronchoscopy and biopsy, bronchial lavage, mediastinoscopy, percutaneous needle biopsy, and thoracotomy. The last two procedures have been shown in several studies to give the highest yield, ${ }^{12}$ and, of the two, needle biopsy is clearly preferable when technically feasible; in experienced hands it is not only a safe and rapid method of obtaining diagnostic material, but it can normally be performed under local anaesthesia and requires only a short stay in hospital. The present study describes a simple technique for percutaneous lung biopsy and analyses the diagnostic yield and morbidity of the method in $\mathbf{1 6 0}$ consecutive procedures.

\section{Patients and methods \\ INDICATIONS AND CONTRAINDICATIONS}

Over a seven-year period 160 biopsies were performed in 149 patients (102 male, 47 female; mean age 58 years, range 9-86). There were three principal indications for the procedure: (a) the investigation of an opacity shown in the chest radiograph when sputum culture, sputum cytology, and bronchoscopy had failed to make a diagnosis; (b) the investigation of a new chest lesion in a patient with a known malignancy to establish whether the chest lesion was related to the previous disease; and $(c)$ the investigation of a region of pulmonary consolidation in a patient with persistent chest infection in whom other techniques had failed to identify the causative organisms.

Contraindications to the procedure included bleeding diathesis, treatment with anticoagulants; contralateral pneumonectomy; pulmonary hypertension; the presence of bullae, suspected hydatid disease, suspected vascular malformation; and seriously impaired lung function from whatever cause.

\section{TECHNIQUE}

The procedure is usually performed under local anaesthesia and the premedication given should not unduly affect the patient's ability to co-operate. ${ }^{3}$ The patient is placed prone for a posterior approach and supine for an anterior approach, the position of the lesion in the chest 
having been determined by recent preliminary posteroanterior and lateral radiographs (using tomography if necessary). Needle biopsy is most easily and safely performed in a unit where biplane fluoroscopy is available; it is, however, possible to biopsy large lesions using only single plane screening. The skin is cleaned, a small scalpel incision made at the planned point of entry, and local anaesthetic instilled down to the pleura. The needle (fig 1) is introduced into the edge of the lesion under fluoroscopic control. With good patient co-operation this can be done during arrested respiration; it is often simpler, however, to perform the manoeuvre during quiet respiration to avoid sudden

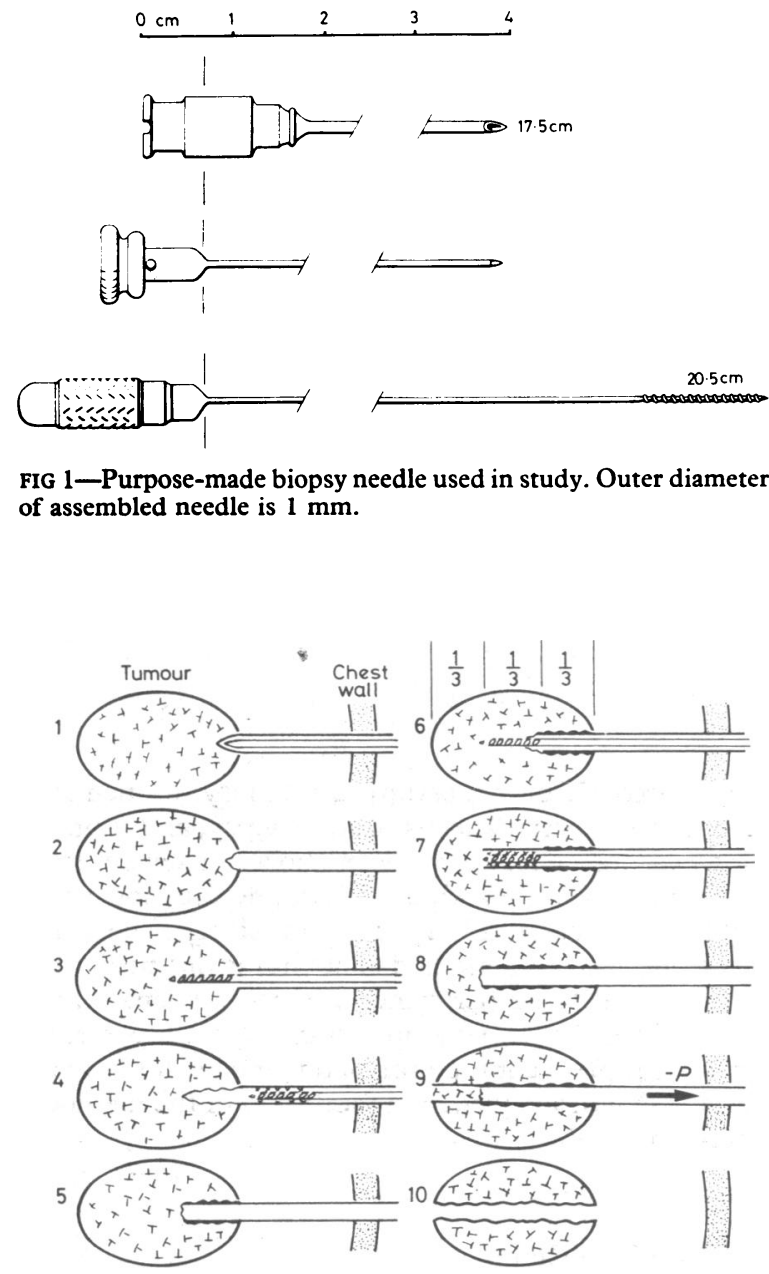

FIG 2-Method for obtaining multiple biopsies using single puncture technique: (1) assembled needle inserted into periphery of tumour; (2) inner stylet withdrawn; (3) corkscrew stylet inserted one-third way into lesion; (4) corkscrew withdrawn sharply to trap fragments of tumour in interstices of screw thread (1st specimen); (5) outer shank advanced one-third way into lesion; (6) corkscrew advanced two-thirds way into lesion; (7) corkscrew held steady and outer shank advanced over it to trap tumour particles in thread; (8) corkscrew withdrawn (2nd specimen); (9) negative pressure applied to outer shank by suction with a syringe and needle advanced to far side of tumour to obtain aspiration biopsy; (10) final specimen withdrawn with needle.

large excursions of the lung during efforts to control respiration. When the biopsy needle has reached the lesion the central stylet is removed and suction applied with a syringe. This is an important preliminary manoeuvre since it may show pus, blood from a vascular lesion, or air from a bronchus. Given that this aspiration is unproductive, the corkscrew needle (fig 2 ) is introduced into the lesion and diagnostic material obtained as described in the figure legend. Note that this manoeuvre may be repeated as many times as desired provided that the outer shank of the needle is not moved from the lesion, and the corkscrew is kept sterile during the preparation of the cytological slides.
This means that multiple specimens can be obtained with only a single puncture of the pleura and lung. Slides are smeared and fixed immediately in the screening room by a histopathologist. After removal of the entire needle the chest is fluoroscoped to check for a large pneumothorax or haemorrhage, and a chest radiograph is obtained in expiration.

All the patients in the present study were then observed in hospital for 24 hours, but in some centres the procedure is performed on an outpatient basis. A chest drain and full resuscitation equipment should be available in the unit where the procedure is performed.

Close co-operation between the radiologist and the departments of histopathology and microbiology is essential for the success of the technique. The most crucial factor in the satisfactory processing of the biopsy material is the help and interest of an experienced cytologist.

\section{Results}

\section{BIOPSY FINDINGS}

The patients were divided into groups according to the outcome of the biopsy and their subsequent clinical management (table I).

TABLE I-Details of groups into which patients were divided according to the outcome of the biopsy and their subsequent clinical management

\begin{tabular}{clcc}
\hline Group No & Category & No of biopsies & No ("., $)$ of patients \\
\hline 1 & Positive for malignancy & 85 & $80(53 \cdot 7)$ \\
2 & Positive for infection & 11 & $10(6 \cdot 7)$ \\
3 & Useful clinical & 26 & $23(15 \cdot 5)$ \\
4 & information & 19 & $17(11.4)$ \\
5 & Frue negative & 9 & $9(6.0)$ \\
6 & Lost to followe & 10 & $10(6 \cdot 7)$ \\
\hline & & 160 & $149(100)$ \\
\hline
\end{tabular}

Group 1-Primary bronchial carcinoma was diagnosed in 71 of the 80 patients with malignant disease, and the various types of secondary tumour found in the remaining nine included lymphoma (two patients), neuroblastoma, thyroid carcinoma, breast carcinoma seminoma, synovioma, leukaemia, and malignant histiocytosis. There were no false-positive diagnoses of malignancy.

Group 2-In 10 patients a positive diagnosis of infection was made; the organisms cultured included Mycobacterium tuberculosis (five patients), Aspergillus fumigatus (two), Haemophilus influenzae (two), and Escherichia coli (one).

Group 3-In 23 patients no malignant cells were found and no micro-organisms cultured, yet cytological examination of the biopsy material obtained provided information that was influential in directing subsequent clinical management. An analysis of this group of patients is given in table II, which shows that, while two patients had a thoracotomy because of suspicions raised by the biopsy, the cytological report in the remaining 19 encouraged the clinician to adopt a conservative approach to managing the chest lesion. All these patients remain well at present (follow-up range: 9 months to 5 years 6 months).

TABLE II-Analysis of patients in group 3

\begin{tabular}{|c|c|c|}
\hline Biopsy result & No of patients & Outcome \\
\hline $\begin{array}{l}\text { Organised fibrous } \\
\text { tissue }\end{array}$ & 9 & $\begin{array}{l}\text { Well on follow-up from } 9 \text { months to } 5 \\
\text { years } 6 \text { months (mean } 3 \text { years } 5\end{array}$ \\
\hline $\begin{array}{l}\text { Cells such as } \\
\text { lymphocytes, } \\
\text { polymorphonuclear } \\
\text { cells, histiocytes, etc }\end{array}$ & 10 & $\begin{array}{l}\text { Well at follow-up from } 2 \text { months to } 6 \\
\text { years } 8 \text { months (mean } 2 \text { y'ears } 5 \\
\text { months) }\end{array}$ \\
\hline $\begin{array}{l}\text { Tissue suggestive of } \\
\text { granuloma }\end{array}$ & 1 & $\begin{array}{l}\text { Thoracotomy and biopsy: rheumatoid } \\
\text { nodule }\end{array}$ \\
\hline $\begin{array}{l}\text { Tissue suggestive of } \\
\text { lymphoma }\end{array}$ & 1 & Thoracotomy and biopsy: benign \\
\hline Iron pigment, & 1 & $\begin{array}{l}\text { No further action taken. Well at follow- } \\
\text { up to date ( } 3 \text { years) }\end{array}$ \\
\hline Calcium/fibrous tissue & 1 & $\begin{array}{l}\text { No further action taken. Well at follow- } \\
\text { up to date ( } 4 \text { years) }\end{array}$ \\
\hline
\end{tabular}

Group 4-In 17 patients the cytology and microbiology were described as negative. Follow-up in this group has ranged from month to 6 years 8 months (mean 3 years and 3 months), and all 
patients remain well. Two patients each had two negative biopsy results. Four patients were referred for thoracotomy after the negative biopsy result. In all four the benign nature of the lesion was confirmed; the lesions found included a lipoma, a hamartoma, and resolving infarcts.

Group 5-Nine patients in whom the biopsy result showed no evidence of malignancy or infection later proved to have a malignant neoplasm. This is a false-negative rate of $6.04 \%$. The diagnosis was made at thoracotomy in three and at necropsy in six.

Group 6-Ten patients out of the original 149 have been lost to follow-up: three have died (no necropsy) and two have gone abroad; two were treated for tuberculosis (though acid-fast bacilli were never isolated, and follow-up has not been at this centre) and in three no further information is available.

\section{COMPLICATIONS}

The commonest complication of the procedure was a pneumothorax. This occurred after 38 biopsies (23.7\%). In most patients the pneumothorax absorbed spontaneously, and in only two patients $(1.3 \%$ of biopsies) was it necessary to insert a pleural drain.

Thirteen patients ( $8 \%$ of biopsies) showed evidence of minor haemorrhage after the procedure: two had a small haemoptysis and 11 developed a small haematoma at the biopsy site as seen in the postprocedural chest radiograph. None of these patients required any treatment. In one patient the biopsy needle entered a branch of the pulmonary artery, and in two other patients pulmonary veins were punctured; none of the patients suffered any ill effects from these mishaps.

No fatalities and no long-term morbidity occurred in our series as a result of the procedure.

\section{Discussion}

The technique of needle biopsy of pulmonary lesions is increasingly gaining acceptance as a rapid and relatively safe diagnostic procedure. The method has been shown in several series to yield clinically useful information in roughly $80-90 \%$ of cases, with a surprisingly low incidence of serious complications. $^{4-7}$ The method is particularly useful in investigating peripheral lung lesions where the results of less invasive methods of diagnosis, such as bronchoscopy and transbronchial biopsy, often prove negative, and where an exploratory thoracotomy may be the only alternative to percutaneous biopsy.

A negative biopsy result does not of course exclude disease ${ }^{8}$; the absence of malignant cells in a biopsy specimen taken from a malignant tumour may simply represent a sampling error, and the likelihood of this happening is increased if there are areas of necrosis in the tumour. Even the positive demonstration of inflammatory cells, fibrous tiśsue, or bacteria does not necessarily exclude the presence of a neoplasm, since obstruction and infection commonly occur in areas of lung adjacent or distal to such lesions. The incidence of false-negative diagnoses may be reduced by a policy of multiple successive biopsies if no definite diagnosis is obtained at first, and this approach is advocated by several authors. ${ }^{159}$ In the case of a suspected tumour the minimum requirement for the acceptance of a tumour-negative biopsy specimen should be three samplings. ${ }^{9}$ In a proportion of cases the biopsy result may be negative for both malignancy and infection yet may still provide clinically useful information that influences subsequent management. Twenty-three patients in the present series came into this category (table II), and in most of them the information obtained was influential in determining whether or not a thoracotomy was performed. It must be remembered, however, that in all these patients the result of the needle biopsy was only one item of diagnostic information among many others. These included the clinical history, the symptoms and physical signs, the radiographic features of the lesion, and the results of laboratory tests on sputum and blood. All these factors together with the lung biopsy result were taken into account in deciding whether to proceed to a thoracotomy, and the favourable outcome of the patients in groups 3 and 4 in this series attests as much to the clinical acumen of the responsible physicians as to the reliability of the biopsy procedure.
Reported complications of percutaneous lung biopsy include pneumothorax, haemoptysis, pulmonary or pleural haemorrhage, air embolism, tumour embolism, tumour implantation in the biopsy track, bronchopleural fistula, and empyema. ${ }^{3} ?^{0-11}$ Despite this alarming list of potential hazards, the incidence of complications is relatively low, the commonest being pneumothorax. The pneumothorax rate after needle biopsy depends on several factors: the selection of cases is clearly important since a pneumothorax occurs more often with small central lesions that present a difficult target than with large lesions adjacent to the pleura; other relevant factors include the diameter of the biopsy needle, the number of punctures performed at one sitting, and the experience of the operator. Experience reduces the pneumothorax rate because it increases the likelihood of obtaining a good biopsy specimen at the first attempt, and because the increased skill and confidence of the operator usually reduce the period that the needle remains in the lung, thereby minimising the risk of tearing the pleura. The graph in fig 3 shows the steady reduction in the pneumothorax rate associated with the increasing experience of one operator in the present series. The apparent

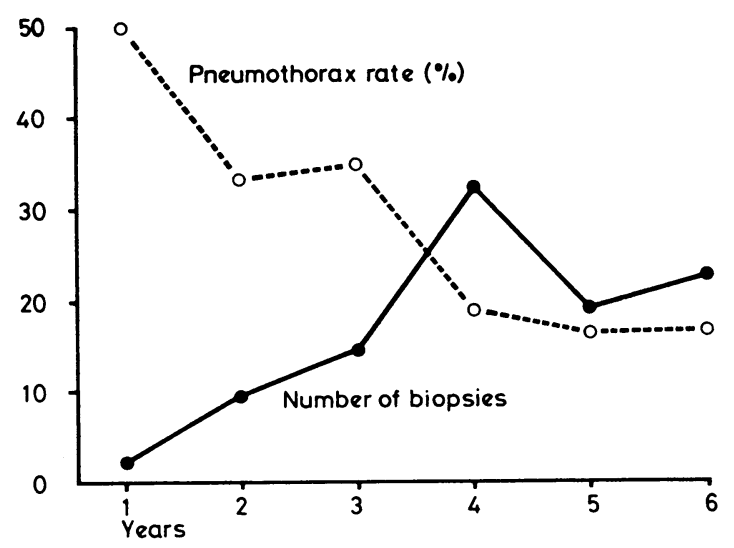

FIG 3-Graph showing decreasing incidence of pneumothorax after needle biopsy of lung as experience of operator increases.

incidence of pneumothorax after lung biopsy also depends on how diligently it is searched for after the procedure; in the present series (which is based on the biopsy of lesions of all sizes in every part of the lung fields) a pneumothorax was looked for in an expiration chest radiograph in all cases after the procedure. Our pneumothorax rate of $23.7 \%$ therefore includes many that were only just detectable by the radiologist; this incidence nevertheless compares favourably with the reported incidence in other large series. ${ }^{25}$

The number of cases requiring insertion of an intrapleural drain was particularly low in the present series $1.3 \%$ of biopsies). We think that the explanation for this lies in the design of the biopsy needle used (figs 1 and 2), which enables multiple specimens to be obtained from an intrapulmonary lesion through only a single puncture track. Nordenström, ${ }^{\circ}$ using a needle similar in design to that described in the present study, has also noted a decreased incidence of complications in comparison with series performed using simple aspiration needles, drills, or cutting instruments. Methods described for reducing the pneumothorax rate after percutaneous lung biopsy include the injection of the patient's own coagulated blood to seal the needle track on withdrawal, and the routine breathing of oxygen by the patient during the procedure so that any gas escaping from the lung into the pleural space is rapidly absorbed. Neither of these techniques was used in the present series.

Any assessment of the potential risks of needle biopsy must take into account the fact that the procedure is being performed as an alternative measure to thoracotomy in most cases. The 
benefits of obviating unnecessary thoracic surgery are obvious, and as more clinicians are becoming aware of the diagnostic accuracy of percutaneous needle biopsy the technique is becoming established as one of the mainstays of diagnosis in chest disease.

We thank Dr E Pearse and Dr R Heaf for their expert help in examining the cytological material in this study, Dr J P Lavender and Dr N B Bowley for their permission to include some of their cases in the series, Mr D Simmonds for preparing the figures, and Miss J Lewis for typing the manuscript.

\section{References}

1 Sargent EN, Turner AF, Gordonson J, Schwinn CP, Pashky O. Percutaneous pulmonary needle biopsy. Report of 350 patients. $A f R$ 1974; 122:758-68.

2 Walls WJ, Thornbury JR, Naylor B. Pulmonary needle aspiration biopsy in the diagnosis of Pancoast tumours. Radiology 1974;111:99-102.
${ }^{3}$ Meyer JE, Furrucci JT, Janower ML. Fatal complications of percutaneous lung biopsy. Review of the literature and report of a case. Radiology $1970 ; 96: 47-8$.

4 Nordenström B. A new technique for transthoracic biopsy of lung changes. Br f Radiol $1965 ; 38: 550$.

${ }^{5}$ Sinner WN. Pulmonary neoplasms diagnosed with transthoracic needle biopsy. Cancer 1979;43:1533-40.

${ }^{6}$ Walli AF, McCormack LJ, Zelch M, Reich NE, Belovich CT. Aspiration biopsies of chest lesions. Radiology 1978;127:35-40.

7 Lauby VW, Burnett WE, Rosemund GP, Tyson R. Value and risk of biopsy of pulmonary lesions by needle aspiration. Twenty-one years' experience. 7 Thorac Cardiovasc Surg 1965;49:159-72.

${ }^{8} \mathrm{Jereb} M$. The usefulness of needle biopsy in chest lesions of different sizes and locations. Radiology 1980;134:13-5.

${ }^{9}$ Nordenström B. Transthoracic needle biopsy. In: Anacker H, Gullotta U, Rupp N, eds. Percutaneous biopsy and therapeutic vascular occlusion. International Symposium Munchen 1979. New York: Thieme-Stratton Inc, 1980.

${ }^{10}$ Sinner WN. Complications of percutaneous transthoracic needle aspiration biopsy. Acta Radiol (Diagn) (Stockh) 1976;17, fasc 6:813-25.

11 Allison DJ. Needle biopsy of the lung. Br $\mathcal{F}$ Radiol 1978;51:70.

(Accepted 9 December 1980)

\section{Dealing with the Disadvantaged}

\section{Communicating with patients with a language problem}

\section{JANET THRUSH}

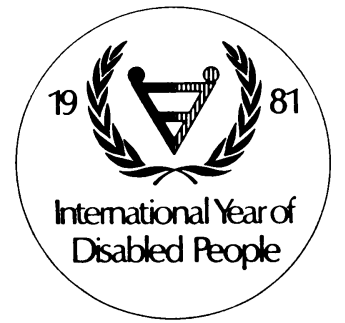

When the dysphasic patient enters your surgery or clinic, there may be no immediate indication that there is anything wrong with his speech. Frequently used phrases such as greetings and responses to questions such as "How are you ?" often remain intact even if the patient has a considerable problem in using and understanding speech. Alternatively, comprehension may be almost normal but the patient unable to say more than a few words, and those not always appropriately. In spite of this wide variation, a few rules for the doctor can help every patient to make the maximum use of his ability to communicate.

(1) Talk slightly more slowly than you would normally, for the same reason that it is easier to understand a foreign language if it is spoken slowly.

(2) Use simple direct sentences without complicated syntax.

(3) Do not "talk down" to the patient.

(4) Do not use "either ... or" questions-for example, "Do you still live with your daughter or are you on your own now ?" Ask each part of the question separately.

(5) Do not rush to finish sentences for the patient; give him time.

(6) Use other clues to help the patient understand, especially when changing the topic-for example, point to the diary when discussing a further appointment.

(7) Reduce extraneous noise by closing windows and doors;

Newton Ferrers, Devon

JANET THRUSH, LCST, speech therapist the dysphasic person often finds it difficult to focus on the sound of speech against a noisy background.

(8) Pay attention when the patient is searching for words; if you fill in the gaps by clicking a Biro or looking through the notes he will be unable to concentrate.

(9) Lip-reading sometimes helps dysphasic patients, so make sure you are in a good light, facing the patient, and keep your hands away from your mouth when you speak.

(10) If a relative is present do not leave the patient out and talk only to the relative; this is insulting. If it is necessary to talk mainly to the relative in the patient's presence, apologise to the patient. It is significant that the physically handicapped felt sufficiently strongly about this to call their radio programme "Does he take sugar?"

(11) Do not underestimate the patient's ability to understand; an amazing amount can be gleaned from expression, vocal tone, and the occasional comprehended word. This is particularly important on ward rounds. Much distress is unnecessarily caused by nursing and remedial staff underestimating comprehension.

(12) Keep the atmosphere relaxed whatever-the pressures on your time; even normal speakers tend to forget words when they feel harassed.

(13) Important instructions should be put into writing; dysphasic patients, even those who have good speech, often have difficulty in retaining new information.

(14) If an eye test has to be given it may be helpful to know that most patients can match similar letters, even when they are unable to say or write the correct one.

(15) Make sure that the receptionist is aware of the existence of dysphasic problems so that when she is faced with someone searching for words or using words inappropriately, yet possibly swearing fluently, she will not assume that the patient is either drunk or in need of sectioning. 